\title{
Konsepsi Kematian a la Jawa
}

\author{
Sumekar Tanjung \\ Dosen Program Studi Ilmu Komunikasi \\ Universitas Islam Indonesia (UII), Yogyakarta
}

\begin{abstract}
This articles describes important side about death in Java, especially Bejikarto society, in Yogyakarta. They looking at death is not the opposite of life. For them, death as a manifestation of the body's extinction and the new life's genesis that is eternity. In the Javanese culture, all of the life and death's process had the concept and control. This article consist of four parts. First is introduction, describes the construction and an understating of God in their belief. Second, describes about death in Javanese people concept. Third is conceiving the causation of death in terms illness and medical. Fourth, is discussion about how Javanese people preserve the tradition in celebration of death.
\end{abstract}

Keywords: Javanese culture, , Javanese tradition, concpet of death

\begin{abstract}
Abstrak
Tulisan ini menjelaskan sisi penting tentang kematian di Jawa, khususnya masyarakat Bejikarto, Yogyakarta. Mereka memandang kematian bukan lawan dari kehidupan. Mereka memandang kematian sebagai manisfestasi kepunahan tubuh dan lahirnya kehidupan baru yang kekal. Dalam budaya Jawa, seluruh proses hidup dan mati memiliki konsep dan pengaturan masing-masing. Tulisan ini membaginya dalam tiga bagian. Pertama, gambaran mengenai Tuhan yang telah terbentuk dalam pemahaman kepercayaan masyarakat Bejikarto. Kedua, memahami kematian dalam konsep orang Jawa. Ketiga, memahami penyebab kematian dalam hal sakit dan campur tangan medis. Keempat, memahami bagaimana orang Jawa melestarikan tradisi dalam perayaan kematian.
\end{abstract}

Kata Kunci: budaya Jawa, tradisi Jawa, konsep kematian

\section{Pendahuluan}

Kematian terjadi manakala roh berpisah dengan wadag manusia. Kematian membawa kepunahan dari tubuh yang berangsur hancur. Pada orang Jawa, kematian bukan dipandang sebagai masalah yang semena-mena memutuskan benang merah antara rohani dan jasmani tubuh. Kematian dijunjung tinggi dan menghasilkan realitas sosial pada tradisi mereka. 
Secara spesifik tulisan ini bermaksud untuk menguraikan konsepsi kematian pada masyarakat Jawa, tanpa memandang, memilih, dan memihak satu agama tertentu. Alasan pertama karena seluruh agama dan kepercayaan menjanjikan umatnya tentang kehidupan yang tidak musnah ditelan kematian. Kedua, kecintaan orang Jawa pada identitas Jawa-nya tidak dapat dilunturkan dogma ajaran lain, bahkan agamanya sendiri. Karena itu orang Jawa penganut Islam, Kristen, Katholik, Hindu, Budha, memiliki sikap dan pemikiran spiritualisme yang relatif sama, karena alasan utamanya adalah mereka orang Jawa sejati. Ini berarti lebih menitikberatkan pada mereka yang melaksanakan agamanya bercampur dengan keyakinan-keyakinan Jawa.

Tulisan ini merupakan refleksi dari pengamatan terhadap masyarakat Desa Bejikarto, Kabupaten Sleman, Kota Yogyakarta. Letak Desa Bejikarto sekitar 15 kilometer ke arah timur dari perbatasan utama Kota Yogyakarta dan 10 kilometer dari Kelurahan Panembahan utara Prambanan. Desa itu berada di tengah lahan pertanian yang luas dan subur, yang menjadi sumber ekonomi desa. Komunikasi dengan desa sekitar maupun kota cukup lancar dan terbuka, dengan dukungan infrastruktur yang memadai.

Mata pencaharian penduduk beragam, dengan akumulasi terbanyak pada sektor pertanian. Petani pemilik tanah hanya sedikit jumlahnya, sedangkan sebagian besar petani lain bukan pemilik tanah (tuna kisma). Kelompok kedua inilah yang umumnya bekerja sebagai buruh, baik di desa sendiri sebagai buruh tani, maupun di kota sebagai buruh pabrik dan buruh bangunan. Pembahasan diawali dengan uraian singkat gambaran mengenai Tuhan yang telah terbentuk dalam pemahaman kepercayaan masyarakat Bejikarto.

\section{Metode Penelitian}

Kemampuan manusia dalam membangun tradisi budaya, menciptakan pemahaman tentang realita yang diungkapkan secara simbolik, dan mewariskannya kepada generasi penerusnya, sangat tergantung pada bahasa. Bahasa menjadi inti dari komunikasi sekaligus sebagai pembuka realitas bagi manusia. Kemudian melalui komunikasi, manusia membentuk masyarakat dan kebudayaannya. Relasi inilah yang kemudian melahirkan etnografi komunikasi.

Etnografi komunikasi merupakan pendekatan terhadap sosiolinguistik bahasa, yaitu melihat penggunaan bahasa secara umum dihubungkan dengan nilainilai sosial dan budaya. Etnografi komunikasi menggabungkan sosiologi dengan antropologi dalam konteks komunikasi, atau ketika bahasa dipertukarkan (Ibrahim, 1992: 35). Dengan kata lain, etnografi komunikasi melihat perilaku komunikasi dalam 
konteks sosial budaya. Pemikiran inilah yang menjadikan etnografi komunikasi sebagai metode penelitian kualitatif yang digunakan dalam tulisan ini.

\section{Orang Jawa Kenal Tuhan}

"Sampun tinimbalan sowan wonten ngarsanipun Gusti Pangeran, penjenenganipun... Mekaten pawartos lelayu kula aturaken...”

Wujud kepercayaan orang Jawa pada Tuhan umumnya bersifat non doktriner, tidak kaku, dan terbuka. Di mata masyarakat Desa Bejikarto, Gusti Pangeran adalah Tan Kena Kinaya Ngapa (tak dapat disepertikan). Mereka mengkiaskan hubungan Gusti Pangeran dengan manusia secara simbolis, "Koyo kodhok ngemuli leng, koyo kodhok kinemulan ing leng (seperti katak menyelimuti liangnya dan seperti katak terselimuti liangnya).” Jarak antara Tuhan dan ciptaan dianggap tidak dapat diukur lagi, jauh tanpa batas, dekat namun tak bersentuhan, "Adoh tanpa wangenan, cedhak tanpa senggolan.” Karena itulah banyak masyarakat Jawa berupaya memanfaatkan simbolisme pada Tembang Macapat demi meraih dan mendekatkan diri pada Gusti Pangeran.

"Bagi orang Jawa yang penting adalah tahu diri. Dan itu juga berarti, menyadari dan menghormati bahwa Tuhan bebas bergerak dalam hati setiap orang. Bukan seakan-akan agama adalah urusan pribadi, melainkan karena orang sendiri harus merasakan di mana, dan ke mana, Tuhan memanggilnya."
Ungkapan Mandi selaku sesepuh Bejikarto, mendukung ungkapan bahwa orang Jawa membenci dogmatisme, eksklusifisme, fanatisme, dan kesombongan seperti yang diungkapkan Mandi, sesepuh Bejikarto. Dalam budaya Jawa, otonomi orang untuk menemukan sendiri di dasar jiwanya, koordinasi Tuhan sangat dihormati.

Menurut Ciptoprawiro dalam Prabowo (2003: 110), filosofi Jawa di sepanjang sejarahnya selalu berkesimpulan bahwa Tuhan merupakan sangkan paraning dumadi (asal dan tempat kembali semua kejadian). Saat kematian tiba, ada bentuk dan rupa seperti diri manusia itu yang keluar dari tubuh dan bercahaya putih, masyarakat Bejikarto menyebutnya sebagai mayangga seta. Jika bentuk sudah dilihat, maka diam dan mengheningkan cipta dianggap sebagai upaya diri untuk menyatu dengan Tuhan ketika mati.

\section{Meraba Kematian}

Kepustakaan Jawa tidak memandang mati sebagai lawan dari hidup. Sebab, konsep kematian dipandang sebagai akibat adanya kelahiran. Singkatnya, jika tidak ada kelahiran, maka selama itu pula tidak akan ada kematian. Sementara itu bagi masyarakat Bejikarto, hidup selalu ada sebelum maupun sesudah dilahirkan. Maka kematian sering diungkapkan sebagai mulih mulo mulanira (kembali kepada asal mula) 
dalam Serat Wedhatama pada salah satu bait tembang Pucung (Mangkunegara dalam Sabdacarakatama, 1978: 27 ). Ini menyiratkan bahwa kematian bukanlah perjalanan akhir di dunia yang fana.

Masyarakat Bejikarto meyakini hidup di dunia yang hanya sementara sama dengan pengibaratan, "urip neng alam donyo iku mung mampir ngombe" (hidup di dunia itu hanya singgah untuk minum). Kata "minum" mengartikan sebagai kesementaraan, manakala minum sudah cukup, maka perjalanan menuju tujuan akhir dapat dilanjutkan. Seorang manusia harus ingat bahwa perjalanan yang lebih jauh akan menyusul kemudian. Mengingat bahwa dharma besar dalam siklus hidup orang Jawa ada tiga konsep. Orang Jawa sering menyebut sebagai konsep tigaan. Purwa (awal) sebagai langkah permulaan seorang manusia lahir, madya (tengah) merupakan langkah seorang manusia menghadapi kehidupan dewasa hingga tua, dan wasana (akhir) dikatakan sebagai tahap akhir seorang manusia yang sudah tua hingga menjelang kematian (Endraswara, 2006: 100-101).

Dalam pernyataan Mandi, tiga derajat orang mati dibedakan pada segi prosesi atau perlakuan saat jasad akan dikebumikan.

"Mati kuwi oncating sukma seka raga. Wong mati eneng telung derajat. Sepisan, mati utomo, matine wong sing dihormati. Mati madya, mati lumrah. Kaping telu, mati nista, matine wong sing bunuh diri, kecelakaan (Mati adalah lepasnya nyawa dari tubuh. Kematian memiliki tiga derajat. Pertama, mati utama, matinya orang terhormat. Mati madya, mati wajar atau mati biasa seperti yang dialami kebanyakan orang. Derajat ketiga, mati nistha, kematian akibat bunuh diri, kecelakaan.”

Pada serat Asmaralaya dijelaskan bagaimana seorang manusia yang sedang menghadapi sakaratul maut digambarkan. Asmaralaya merupakan kiasan kehidupan setiap manusia. Kiasan yang dimaksud adalah ingat akan kematian atau kesadaran manusia akan kematian. Bahwa Tuhan hakikatnya berwujud cahaya yang memancar dan menyelimuti alam semesta. Jika saat kematian sudah tiba, ada bentuk dan rupa seperti dirinya sendiri keluar dari tubuh dan bercahaya putih (mayangga seta). Jika bentuk semacam itu sudah dilihat, maka diam dan mengheningkan cipta adalah upaya diri untuk menyatu dengan Tuhan (Mulyani, Jurnal Kebudayaan Jawa, No. 2, Agustus 2006: 115).

\section{Kematian: Antara Derita Sakit dan Medis}

Di antara sebab kematian adalah menderita sakit. Sifat sakit ini sama halnya dengan kematian, mudah terjadi kapan saja. Bagi masyarakat Bejikarto, sakit adalah perkara nyaman dan tidak nyaman. Djamaluddin, akrab disapa Dul Sadin, adalah warga desa ini. Ia anak kedua dari lima bersaudara. Dulu ia 
delapan saudara. Tiga lainnya meninggal karena satu sebab: masuk angin!

Peristiwa masuk angin bagi orang Jawa muncul karena orang Jawa memiliki konsep sakit berupa rasa tidak nyaman, tidak enak di badan, yang dipercaya diakibatkan oleh pengaruh angin. Masuk angin sebenarnya bukan istilah medis, namun masyarakat menyebutnya demikian. Gejala yang muncul antara lain perut kembung, mual, nyeri, ditambah tidak bisa kentut dan bersendawa (Rustami, 2009: 85). Bagi orang Jawa angin dianggap masuk ke dalam tubuh manusia melalui pori-pori maupun sembilan lubang tubuh manusia (babahan hawa sanga). Akibat unsur angin yang masuk tubuh yang berlebih maka tubuh mengalami ketidakseimbangan. Sehat bagi orang Jawa adalah keseimbangan, sementara sakit, celaka dan ketidakberuntungan dianggap sebagai ketidakseimbangan.

Akibat adanya perbedaan konsep antara orang Jawa dan medis maka masuk angin pun dipandang berbeda oleh kedua belah pihak. Tidak ada terminologi medis untuk masuk angin sehingga masuk angin hanya dianggap sebagai kumpulan gejala suatu penyakit. Pihak medis menyebut masuk angin sama dengan influenza. Masuk angin dianggap dapat menjadi gejala dari penyakit yang beragam seperti: influenza, hipertensi, diabetes, hepatitis, atau stres pascatrauma. Oleh sebab itu masuk angin oleh pihak medis akan diobati berdasar gejala yang dirasakan pasien.

"Kula nek masuk angin niku teng mata rasane abut nek ajeng melek. Awak rasane aras-arasen dinggo nyambut gawe. Mangkih nek selo nggih ngaso (Saya kalau masuk angin, mata rasanya berat kalau dibuka. Badan rasanya malas kalau dipakai untuk bekerja. Nanti kalau ada waktu luang ya baru bisa dipakai untuk istirahat)," cerita Mbah Sud.

Pada umumnya penderita masuk angin merasakan badan yang lemah, lesu, serta mulut tidak enak untuk makan minum.

"Pokoke nak ses niku rasane mboten enak, pait nika, wah mesti kulo masuk angin niku (Pokoknya ketika saya merokok rasanya tidak enak, lidah pait, wah pasti masuk angin saya ini)."

Orang Jawa membedakan masuk angin berdasar berat ringan gejala, banyak sedikitnya jumlah gejala serta mudah tidaknya dalam proses penyembuhan. Masuk angin kasep, yaitu masuk angin yang dibiarkan oleh penderitanya sehingga membawa kematian mendadak. Akibatnya banyak kematian mendadak yang sering diawali dengan rasa tidak enak badan, sesak napas atau keluar banyak keringat. Ungkapan penyembuh tradisional, K (49 tahun) menguatkan hal ini.

"Angin duduk niku mesti dimulai saking masuk angin biasa, ning mboten diraosake. Lha niku mbebayani, mergane ora ngapangapa mung lingguh njuk seda 
(Angin duduk itu mesti dimulai dari masuk angin biasa, tapi tidak dirasakan. Itu berbahaya soalnya tidak melakukan pekerjaan apapun hanya duduk saja, tibatiba langsung mati).”

Para dokter yang melakukan praktik pengobatan baik di Puskesmas, rumah sakit maupun praktik pribadi sering menjumpai keluhan umum pasien yaitu badannya terasa tidak enak. Mereka mengatakan kepada dokter bahwa dirinya mengalami masuk angin. Sebelum ke dokter mereka sudah melakukan kerokan, minum jamu, dan minum pil kecethit (meskipun namanya pil kseleo, tapi masyarakat di pedesaan percaya kalau pil ini mampu menyembuhkan berbagai penyakit). Oleh sebab itu mereka memeriksakan diri ke dokter yang dianggap lebih tahu karena memiliki peralatan kesehatan yang lengkap. Singkatnya, semua rasa tidak enak atau tidak nyaman yang dirasakan, mereka beri istilah sebagai masuk angin.

Sistem medis pada masyarakat tradisional memiliki sehat-sakit yang berbeda, demikian pula upaya pengobatannya. Pada orang Jawa, Foster dan Anderson (dalam Sudarma, 2008: 139) mengklasifikasi penyebab penyakit yang dianggap berasal dari sistem personalistik atau sistem naturalistik. Pada konsep personalistik, penyakit dipercaya sebagai intervensi dari suatu perantara aktif berupa gaib atau bukan manusia. Pada masyarakat Bejikarto, mereka menyebutnya sebagai penyakit ora lumrah atau tidak wajar. Jenis penyakit ini seperti kelebon, digawe wong, kualat, dan kebendhu. Penyembuhannya dilakukan melalui upacara atau sesaji untuk menetralisir sebab sakit. Konsep naturalistik lebih dianggap sebagai penyakit lumrah atau wajar. Biasanya yang mempengaruhi kesehatan tubuh adalah cuaca, makanan, kuman, dan racun.

Pandangan para antropolog kesehatan membagi penyakit ke dalam tiga model kepercayaan kesehatan, yakni magico-religious model, biomedical model, dan holistic model. Masyarakat Jawa yang kuat sistem tradisionalnya, semua penyakit dijelaskan secara holistik. Model ini menekankan pada aspek harmonisasi atau keseimbangan tubuh, menyangkut lingkungan, sosial budaya, dan perilaku. Kondisi tubuh yang sehat dipandang sebagai keadaan waras atau seimbang antara fisik dan batin. Orang Jawa berpandangan, "batin karep, raga nututi", berarti jika batin berkehendak, maka tubuh pun demikian. Bahwa tubuh, pikiran, dan jiwa atau sukma adalah kesatuan yang saling berpengaruh.

Pada masyarakat Jawa, mereka memiliki paham bahwa tubuh dijaga oleh kakang kawah adhi ari-ari, agar hidup manusia selamat ia harus memahami alam semesta sebagai simbol kekuasaan Tuhan. Ini meliputi empat elemen, kawah (ketuban) untuk arah timur, darah untuk arah selatan, talipusat untuk arah barat, dan plasenta untuk arah utara 
(Endraswara, 2006: 102; Hardjodisastra, 2010: 201) yang berfungsi menjaga kesehatan jiwa dan raga agar selalu dalam keadaan seimbang, dalam konteks memayu hayuning bawana (manusia harus selalu menjaga keselarasan dan keseimbangan) Penyembuhan dimaksud untuk mengembalikan keseimbangan tersebut. Sementara, sembuh atau mati, tidak tahu kapan terjadi.

\section{Memanusiawikan Tradisi}

Di Bejikarto dan daerah lain di Jawa, merayakan kematian terhadap jasad dianggap sebagai satu penghargaan dan penghormatan yang harus dilanggengkan. Bahkan telah dimaklumi bersama bahwa acara tahlilan merupakan ritual seremonial yang biasa dilakukan sebagai satu keumuman masyarakat. Bersama sanak famili, handai taulan dan tetangga yang kesemuanya laki-laki (karena yang memang terlibat dalam ritual ini adalah laki-laki), melakukan dzikir, disertai doa tertentu untuk dikirimkan kepada si mayat.

Rila atau ikhlas, berarti merelakan segala sesuatu secara sadar, merupakan pedoman meskipun seringkali sulit diperoleh, namun senantiasa diusahakan setiap orang. Dalam falsafah Jawa, filosofi bambu disesuaikan dengan unsur sentral kebudayaan Jawa, yakni rila (ikhlas), nrima (bersyukur), dan sabar.

Di Bejikarto, biasanya seremonial ini dilakukan setelah penguburan mayat, yaitu sore hari sebelum adzan maghrib. Selamatan tiga hari kematian (nelung dina) dimaksudkan sebagai upaya ahli waris untuk menghormati orang yang meninggal. Dalam kaitan ini, mereka berkeyakinan bahwa roh orang yang meninggal masih berada di dalam rumah. Namun roh tersebut sudah tidak berada di tempat tidur lagi. Roh sudah berkeliaran untuk mencari jalan agar dengan mudah meninggalkan rumah.

Setelah roh dianggap keluar dari rumah, digelar mitung dina agar dapat keluar dengan lancar. Roh yang sudah keluar akan berhenti sejenak di halaman. Untuk mempermudah jalan, para tetamu menggelar tahlilan untuk mendoakan.

"Tahlilan menika waosan kalimat tayibah. Mangkih tamu-tamu menika dipun paringi sego bancakan kaliyan lawuh (Tahlilan membaca kalimat tayibah. Selesainya, para tamu nanti diberi nasi bancakan dan lauk)."

Kata bancakan dalam nasi bancakan kemungkinan berasal dari tempat tumpeng pungkur, dibuat dari anyaman bambu yang jaraknya renggang. Anyaman ini disebut ancak. Kemudian berkembang dan disesuaikan menjadi bancak. Selain penyebutan nasi bancakan, ada pula yang menyebutnya sebagai nasi berkat (berasal dari bahasa Arab barakah).

Pada hari ke-40 kematian, roh telah menuju alam kubur. Sesajian yang diberikan juga bermacam-macam. Ini 
dimaksudkan sebagai sajian kepada roh dan jasad yang harus disempurnakan, seperti darah, daging, kuku, rambut, tulang, dan otot (Bratawidjaja, 1993: 136). Untuk menyempurnakan kesemuanya, dilakukan nyatus dina atau 100 hari kematian. Sajiannya hampir sama, yang membedakan hanyalah pada pasung, ketan dan kolak. Pasung yang dibuat seperti gunung (payung) dari daun nangka dan diisi bahan dari gandum. Maknanya adalah agar yang meninggal mendapatkan payung (perlindungan). Karena orang yang meninggal diibaratkan akan melewati jalan panjang dan panas, maka untuk dia dibuatkan ketan sebagai alas (lemek) agar kakinya tidak panas. Ketan juga bermakna raketan artinya mendekatkan diri kepada Tuhan. Sajian juga dilengkapi kolak yang berasal dari kata khalik atau kolaq (pencipta). Dengan sajian semacam ini, diharapkan orang yang meninggal akan dengan lancar menghadap Sang Khalik. Ini kemudian berlangsung hingga satu tahun kematian dan dua tahun kematian.

Di hari keseribu (nyewu dinane), sanak famili dan tetangga berdatangan untuk nyumbang (memberikan uang sumbangan). Tradisi ini diharapkan dapat menghibur keluarga yang ditinggalkan sekaligus menjadikan amanat bahwa yang masih hidup juga pasti akan menyusul (mati) di kemudian hari. Tak lepas pula adanya perjamuan yang tersaji tiap acara diselenggarakan. Model penyajian hidangan biasanya variatif, tergantung adat yang berjalan di tempat tersebut. Namun menu hidangan justru lebih dari sekedarnya, atau cenderung mirip menu hidangan yang berbau kemeriahan. Jika sebelumnya tidak memakai makanan sesudah tahlil, biasanya selamatan nyewu memakai makan bersama. Setelah makan bersama lalu dilaksanakan kenduri. Sehingga acara ini terkesan pesta kecilkecilan dan menjadi suatu kelaziman.

\section{Penutup}

Orang Jawa memiliki keterbukaan emosi dan budaya yang tinggi. Mereka bisa menerima apapun yang datang, sekaligus menyeleksi dan meramunya hingga menghasilkan model baru yang dirasa tepat. Perlu dicatat, segala konsepsi yang telah dipaparkan hanyalah fenomena formal. Pergulatan inti orang Jawa dalam menjemput dan memaknai proses daur hidup manusia tidak dapat digambarkan oleh siapapun. Dalam pencariannya, tidak jarang mereka terbentur banyak hal dan semua bermuara pada spiritualisme masing-masing. Puncaknya, spiritualisme Jawa berharap mampu menggapai ngangkah ningrat nunggal Hyang (menggapai keheningan tingkat atas menyatu dengan Tuhan) (Nitiharjo dalam Mulyana, Jurnal Kebudayaan Jawa, No. 2, Agustus 2006: 12). Sejumlah kajian, termasuk tulisan ini, hanya sedikit meraba mengenai konsepsi kematian di Jawa. 


\section{Daftar Pustaka}

Bratawidjaja, Thomas Wiyasa. 1993. Upacara Tradisional Masyarakat Jawa. Jakarta: Sinar Harapan.

Endraswara, Suwardi. 2006. Mistik Kejawen: Sinkretisme, Simbolisme dan Sufisme dalam Budaya Spiritual Jawa. Yogyakarta: Narasi.

Ibrahim, Abd. Syukur. 1992. Panduan Penelitian Etnografi Komunikasi. Surabaya: Usaha Nasional.

Mulyana. "Spiritualisme Jawa: meraba Dimensi dan Pergulatan Religiusitas Orang Jawa.” Kejawen: Jurnal Kebudayaan Jawa., II (Agustus 2006), hal. 12.

Mulyani, Hesti. "Naskah Serat Asmaralaya: Sakaratul Maut dalam Konsep Kejawen.” Kejawen: Jurnal Kebudayaan Jawa. II (Agustus 2006), hal. 115.
Nitihardjo, Soeprapto. 2001. Andharan dan Tafsir Filsafat Hanacaraka. Yogyakarta: Tiara Wacana.

Rustami, A. 2009. A-Z Tips Hidup Sehat Sehari-hari. Yogyakarta: Wahana Totalita Publisher.

Sabdacarakatama, Ki. 2010. Serat Wedhatama: Karya Sastra K.G.P.AA. Mangkunegara IV. Yogyakarta: Narasi.

Sudarma, Momon. 2008. Mengenal Variasi Layanan Pengobatan Alternatif. Sosiologi untuk Kesehatan. Jakarta: Salemba Medika.

Prabowo, Priyo Dhanu. 2003. Pengaruh Islam dalam Karya-karya R.Ng.Ranggawarsita. Yogyakarta: Narasi. 
Jurnal komunikasi, Volume 8, Nomor 1, Oktober 2013 